\title{
Retraction Note to: Groundwater resource pollution detection and home sports training intervention based on image super-resolution processing
}

\author{
Huiying Dai ${ }^{1}$
}

Published online: 15 November 2021

(c) Saudi Society for Geosciences 2021

Retraction Note to: Arabian Journal of Geosciences (2021) 14: 1657 https://doi.org/10.1007/s12517-021-07972-w

The Editor-in-Chief and the Publisher have retracted this article because the content of this article is nonsensical. The peer review process was not carried out in accordance with the Publisher's peer review policy. The author has not responded to correspondence regarding this retraction.

The original article can be found online at https://doi.org/10.1007/ s12517-021-07972-w.

Huiying Dai

chunxinglu795819@163.com

1 Hubei University of Education, Wuhan 430205, Hubei,

China 